\title{
Differentiation and integration: off-site resettlement planning practice in New Beichuan after 5.12 Wenchuan Earthquake
}

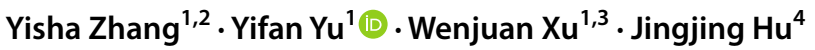

Received: 5 September 2017 / Accepted: 19 June 2019 / Published online: 2 July 2019

(c) The Author(s) 2019

\begin{abstract}
This article explores the spatial differentiation and integration between the post-disaster victims and the indigenous peasants 8 years after a rapid off-site resettlement oriented by governments in New Beichuan. Data were broadly collected from placement documents, questionnaires, interviews and site measurement by empirical research and on-site investigation in 2014. The resettlement plan was introduced and analyzed for housing resettlement, open space systems, public facilities allocation and resettlement policies. Based on statistical analysis of the questionnaire data and observation on the usage of the built environment, problems with the spatial usage and mismatches between the specific spatial requirements and subjective planning intention of integration are analyzed and preliminary findings are shown. The results showed that the excessive pursuit of speed and deficiency in economically self-sustaining efforts might contribute to insufficient attention given to spatial, social and economic aspects and leads to inevitable and long-standing problems, such as housing quality problems, neighborhoods management and security concerns, contradictions between the housing layout and local living habits, different spatial usage preferences between the indigenous peasants and post-disaster migrants, and disequilibrium of public facility allocation.
\end{abstract}

Keywords Post-disaster reconstruction · Integration · Off-site resettlement · Planning practice $\cdot 5.12$ Sichuan Earthquake $\cdot$ New Beichuan $\cdot$ China

\section{Introduction}

Catastrophic natural disasters like earthquakes, tsunami, hurricanes and global climate change disrupted not only physical stock and infrastructure systems of the disaster areas, but also social and economic systems referring to the livelihoods of the afflicted people.

Electronic supplementary material The online version of this article (https://doi.org/10.1007/s1106 9-019-03649-6) contains supplementary material, which is available to authorized users.

Yifan Yu

yuyifan@tongji.edu.cn

Extended author information available on the last page of the article 
As part of the results of social spatial system disruption, the reconstitution of communities may contribute to new problems, including residential differentiation (Kawachi and Lisa 2003) or housing segregation caused by factors such as socioeconomic status, spatial assimilation and immigration (Iceland 2009; Briggs and Wilson 2005; Momeni 1986; Murdie 2001), and lead to effects of reallocation, unequal living standards and poverty (Cutler and Glaeser 1995; Danziger and Haveman 2001; Henry 2004; Massey and Denton 1993; Sharkey 2013).

This kind of disruption and interruption caused by unexpected events may extend over time and require a long time to await reconstruction and recovery on both physical and unphysical aspects. In terms of the physical dimensions, site selection, spatial layout, housing design and infrastructure repair are usually presented as crucial issues during the response and reconstruction process (Oliver-Smith 1991). The unphysical factors including economic development and population participation could also play significantly important roles in post-disaster reconstruction, especially in the off-site resettlement, by helping the survivors to recover from the economy stagnates and social networks weaken (Barenstein and Pittet 2007; Blanco et al. 2009; Cernea 1988; Davidson et al. 2007; Lizarralde 2002, 2011; Oliver-Smith 1991; Partridge 1989).

Therefore, the successes of post-disaster resettlements refer to not only a matter of delivering and reconstructing the physical environment, but also other issues concerning social, economic and political aspects (Barenstein and Pittet 2007; Oliver-Smith 1990, 1991; Partridge 1989). According to Coburn et al. (1984) and Cernea (1988), the key evaluation standards of a successful resettlement should be self-reliant (Coburn et al. 1984), economically sustainable and development-oriented (Cernea 1988). In addition, the relationship between the space and the migrants, the equity and transparency of the resettlement process, and the self-development capability of the communities could also be critical factors in a long-term response and recovery after the reconstruction (Barenstein and Pittet 2007; Cernea 1988; Coburn et al. 1984; Johnson 2008; Levine et al. 2007; Oliver-Smith 1990, 1991; Scudder and Colson 1982; Zhang and Peacock 2009).

Past works on post-disaster reconstruction focused on two aspects, theory and model building through theoretical and quantitative analysis, and objective phenomenons reporting based on factors and patterns identification (Yi and Yang 2014). The major research themes included infrastructure issue, reconstruction approach, governance issue, stakeholder analysis and so on (Yi and Yang 2014).

However, compared to developed countries, researches in developing countries such as Asia and South America are still lagging, especially in housing and social fields of postdisaster reconstruction (Levine et al. 2007). Studies on integrated development and sustainable construction with more comprehensive and holistic views should be conducted in the future research field as critical issues (Levine et al. 2007; Yi and Yang 2014).

In this article, a typical rapid government-oriented off-site post-disaster resettlement planning practice in China's Sichuan Province is introduced, which is also a special case for the site selection and rapid time-consuming period compared with other post-disaster resettlements (see Table 1). The post-disaster migrants in this case were successfully relocated to a newly planned city called New Beichuan after 5.12 Wenchuan Earthquake. At the same time, the indigenous peasants who used to live on the site of New Beichuan were also resettled to the new city (see Fig. 1). The post-disaster migrants and the indigenous peasants were provided with differently located but similarly designed resettlement communities (see Fig. 3).

Based on an on-site investigation in 2014, useful descriptive data and analysis are provided in this paper to shed light on the question: "By providing similarly designed but 


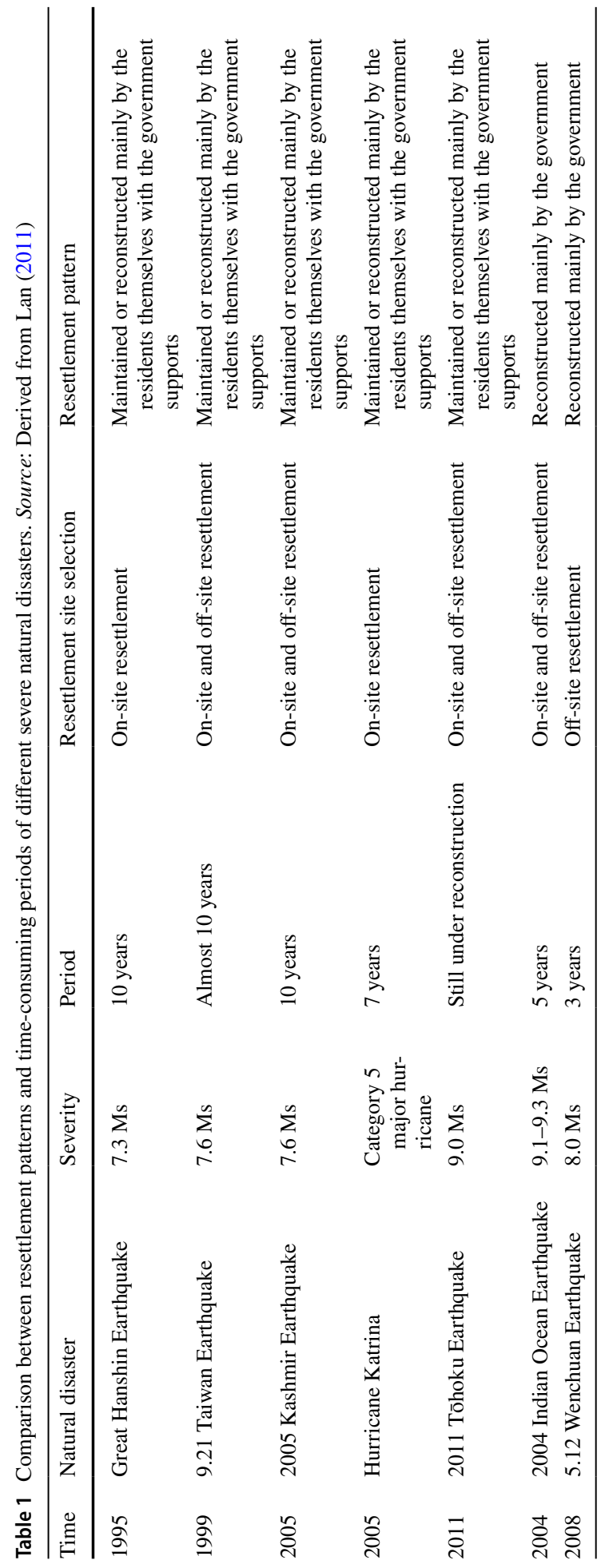




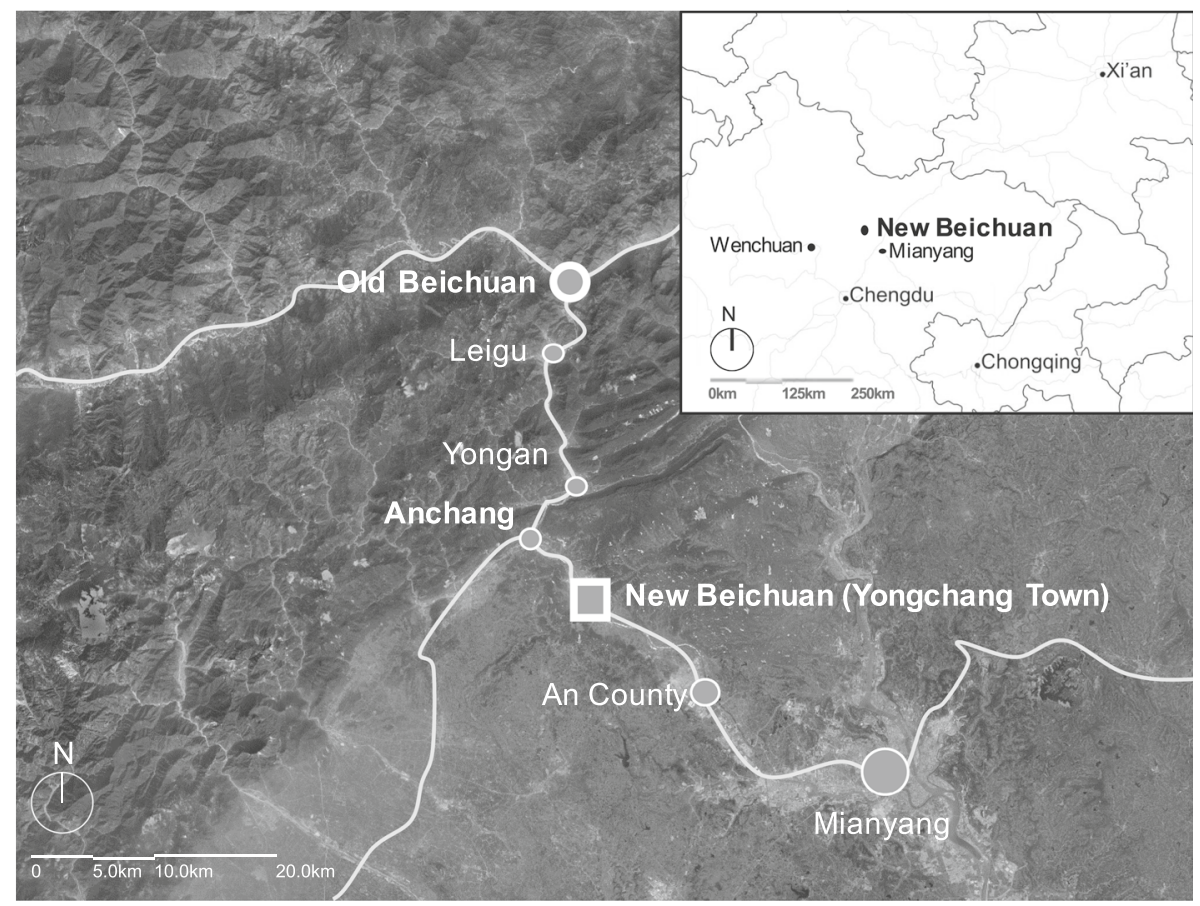

Fig. 1 Location of the Old Beichuan and the New Beichuan. (Source: Base map from Google Earth 2017 and elaborated by authors)

differently located resettlement sites for the indigenous peasants and the post-disaster migrants from the Old Beichuan, how well did the planning and project implementation enable the "integration" of the two groups of people to the new place?"

\section{Research methods}

\subsection{Data collection techniques}

Various methods including on-site investigation, interviews and questionnaire surveys were adopted in this study. In the December of 2014, an on-site investigation was conducted on the post-disaster off-site resettlement of New Beichuan. Related data were collected from questionnaire surveys, site investigation of the built environment and semi-structured interviews with the residents and the community leaders.

\subsubsection{Questionnaire survey}

A total of 263 questionnaires were released to the residents in two parts. In the first part, 203 paper questionnaires (see Appendix 1 in ESM) were distributed to the community staff in each of the four neighborhoods separately. Each neighborhood received around 50 questionnaires (see Table 2). Then the community staff were instructed to distribute 
Table 2 Questionnaire quantity statistics. (Source: From questionnaires and interviews)

\begin{tabular}{lrrrrr}
\hline & $\begin{array}{l}\text { Erma Com- } \\
\text { munity }\end{array}$ & $\begin{array}{l}\text { Yulong } \\
\text { Community }\end{array}$ & $\begin{array}{l}\text { Muxi Com- } \\
\text { munity }\end{array}$ & $\begin{array}{l}\text { Xinchuan Com- } \\
\text { munity }\end{array}$ & Total \\
\hline Number of households & 3131 & 2030 & 3166 & 2350 & 10,677 \\
Released paper questionnaires & 53 & 50 & 50 & 50 & 203 \\
Valid paper questionnaires & 53 & 48 & 40 & 46 & 187 \\
Structured interviews & 11 & 12 & 17 & 18 & 58 \\
Total & 64 & 60 & 57 & 64 & 245 \\
\hline
\end{tabular}

those questionnaires randomly to a variety of residents in their neighborhoods. Eventually, 187 valid self-administered questionnaires were collected from the community center (see Table 2). In the second part, our investigators ( $\mathrm{Wu} \mathrm{Lu}, \mathrm{Xu}$ Wenjuan, Yang Qianwen and Zhang Yisha) randomly interviewed 58 residents who occurred in the different open spaces of the four neighborhoods and were willing to accept the interviews. The investigators filled out the questionnaires according to the face-to-face interviews with the residents. The interviews were done according to both the questionnaires (see Appendix 1 in ESM) and the question list (see Appendix 2 in ESM). Most of the invitees were willing to accept the interview. Declination of the interviewees existed but only occupied a very small proportion.

In total, 245 valid questionnaires were collected from 261 questionnaires with a $92 \%$ effective rate. Among all the respondents, $43 \%$ were male and 57\% were female. $32 \%$ respondents were from the Qiang ethnic minority, and $65 \%$ were Han ethnicity. $57 \%$ of respondents had received high school education or above.

However, considering the uncontrollability of the community staff's behavior, the randomness of some questionnaires in the first methods might be influenced to some extent. Some questionnaires could be filled out by the acquaintance of community staff who performed actively in the community events, or residents who frequented the community center and willing to complete the questionnaires. The community staff might believe that those responses could reasonably represent the opinions of the residents and their households in their neighborhoods. Although the detailed process of data collecting could be hardly known and monitored to make sure whether the staff distributed the questionnaires randomly, the 187 completed questionnaires could still give valuable information. If we assume that each questionnaire represented the opinion of one member of a household, then the 187 completed questionnaires would represent almost 187 households from the neighborhoods and represent the experiences of the residents in the neighborhoods as an opportunistic sample.

\subsubsection{Interviews}

Semi-structured interviews were conducted with 58 residents and leaders from the community center and NGOs. Fifty-eight semi-structured interviews were conducted with the residents at different places, including the green spaces in the neighborhoods, street shops, community gates, green spaces on the river, etc. Every structured interview with the residents took around $15 \mathrm{~min}$. The community and NGO leaders were also interviewed in the community centers of the four neighborhoods and the activity places of NGOs. Every 
semi-structured interview with the leaders took around 30-60 min. Questions of the structured interviews were according to the questionnaire (see Appendix 1 in ESM) and question list (see Appendix 2 in ESM). All the interviews were conducted in Chinese, recorded digitally and turned into text transcript.

\subsubsection{On-site investigation}

The on-site investigation was conducted between December 8 and December 12 in 2014 by 4 investigators ( $\mathrm{Wu} \mathrm{Lu}, \mathrm{Xu}$ Wenjuan, Yang Qianwen and Zhang Yisha).

The contents of the investigation included:

(1) the utilization of the public facilities in the city;

(2) the utilization of the public spaces in the city;

(3) the design and implementation (construction quality) of the projects;

(4) the service quality of the communities such as the stacking and cleaning of the garbage;

(5) and the relationship between neighbors and families.

\subsection{Analysis methods}

The resettlement plan was introduced and analyzed for housing resettlement, open space systems, public facilities allocation and resettlement policies. Based on statistic analysis of the questionnaire data and observation on the usage of the built environment, problems with the spatial usage and mismatches between the specific spatial requirements and subjective planning intention of integration were analyzed and preliminary conclusions are shown.

\section{The Sichuan Earthquake and off-site resettlement master plan}

On May 12, 2008, an earthquake measuring at a magnitude of 8.0Ms (China Earthquake Administration 2008) took place at Wenchuan in Sichuan Province of China, which led to enormous spatial and socioeconomic damage to the local residents. ${ }^{1}$ The Old Beichuan $^{2}$ was one of the most severely afflicted areas, where only around 13,600 people survived out of the total population of 27,000 in the city (Sina News 2018a). $80 \%$ of buildings in the city were ruined (Ma and Yang 2010). The roads and infrastructures were seriously damaged, and a huge landslide after the earthquake caused irreversible damage to the surrounding ecological environment. The whole city almost fell into ruins and was considered as too vulnerable to be reconstructed. Therefore, in the August of

\footnotetext{
12008 Sichuan Earthquake, which occurred at 14:28:01 on May 12, 2018, in the Sichuan Province of China, measuring at a magnitude of 8.0 Ms (China Earthquake Administration 2008) and suffering a series of strong aftershocks exceeding 6.0 Ms (China Earthquake Administration 2009). The earthquake led to enormous spatial and socioeconomic damages. Over 69,000 people lost their lives in the quake, including 68,636 in Sichuan Province. 374,176 were reported injured, with 18,222 listed as missing as of July 2008 (Sina New 2008b). In addition, the earthquake left about 4.8 million people homeless (Agence FrancePresse 2008) and the direct economic loss reached 8452 billion RMB (Baidubaike 2018).

2 The Old Beichuan is located in Sichuan Province and used to be the county town of Beichuan Qiang Autonomous County.
} 


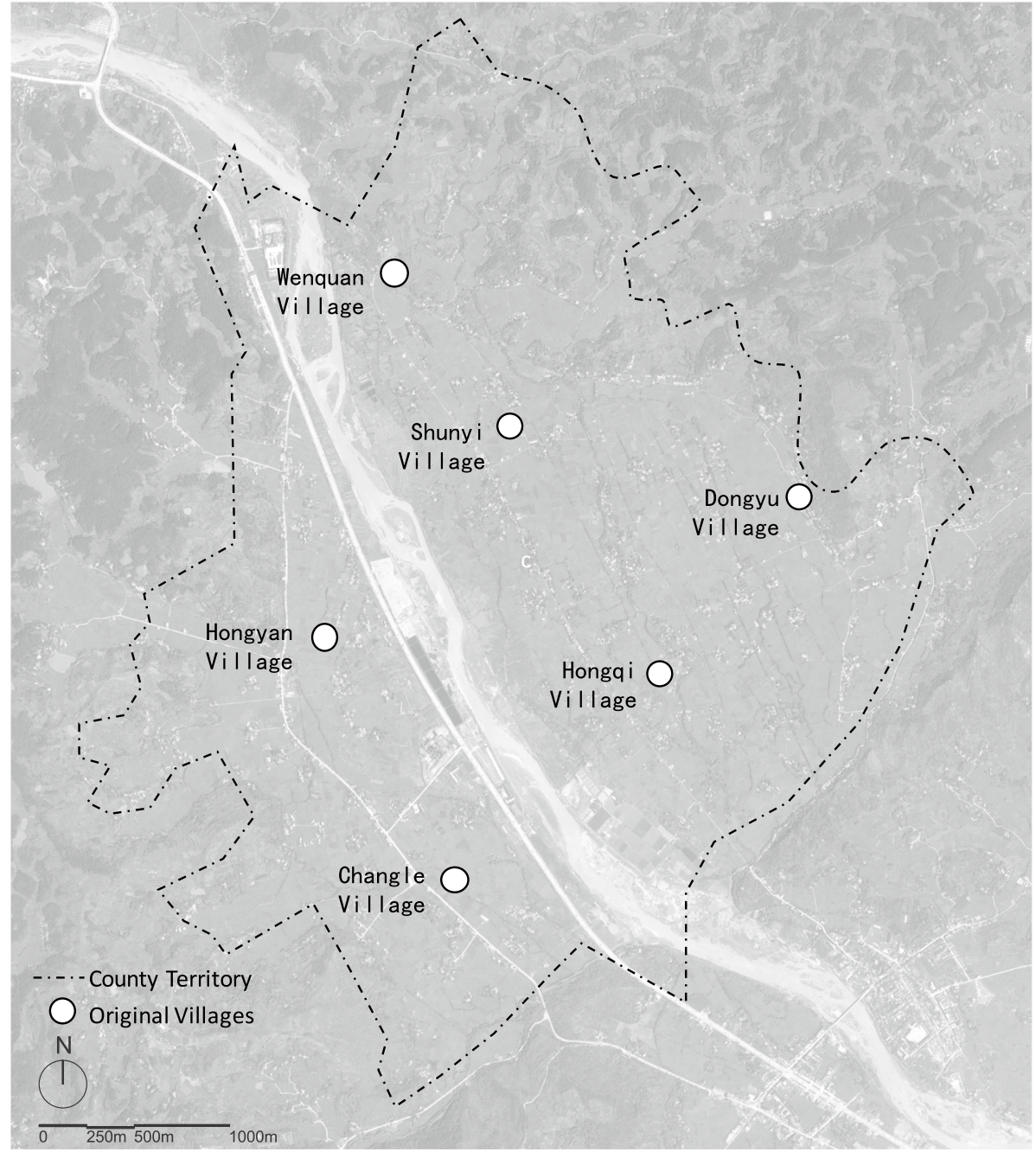

Fig. 2 Location of the original six villages on the site of New Beichuan. (Source: Base map from Google Earth 2017 and elaborated by authors)

2008, an off-site resettlement plan was put forward by the Central Government with the agreements of the $95.29 \%$ surviving residents (Ma and Yang 2010). Beichuan became the first and only off-site resettlement city after the Sichuan Earthquake.

After repeated comparisons of different plans and comprehensive consideration of the safety and development of the city, the site of New Beichuan was selected on the fringe farmland $23 \mathrm{~km}$ away from the Old Beichuan (see Fig. 1) with a new name called Yongchang Town. The six villages on the site (Changle Village, Hongyan Village, Shunyi Village, Hongqi Village, Wenquan Village and Dongyu Village) (see Fig. 2), which used to belong to An County, were also allocated to the New Beichuan city. The 11,955 indigenous peasants (Huaxi City News 2010) from the six villages, who lost their 
farmland, were relocated to the new city, and a concentrated resettlement community was planned for the land-lost peasants of the six villages with their agreements.

On September 25, 2010, 2 years after the earthquake, the construction of New Beichuan was completed. According to the resettlement master plan, the construction land area of New Beichuan would be 2.8 square kilometers and the population would be around 30,000 people in 2010. An area of 1.4 square kilometers would be used for living functions, and the other 1.4 square kilometers would be used for the infrastructure construction of the Shandong industrial zone. By 2015, the construction land area would be 6.03 square kilometers and the population would be around 50,000 people. By 2020, the construction land of the city would cross the Anchang River and reach 7.13 square kilometers, and the population will be around 70,000 people (Baidubaike 2018). However, according to the statistics of the government, the total population of the New Beichuan (Yongchang Town) was only around 42,000 people in 2017, which consisted of 27,512 resident population ${ }^{3}$ and more than 15,000 floating population ${ }^{4}$ (Government Website of Beichuan 2018).

\subsection{Housing resettlement of post-disaster migrants and the indigenous peasants}

Considering the apparent differences between the post-disaster migrants and the indigenous peasants on ethnicity, registered residences and resettlement policies, separate communities were built for the two groups of people in the resettlement master plan. ${ }^{5}$

The communities of the post-disaster migrants were on the north side, which consisted of two neighborhoods called Erma and Yulong. The communities of the indigenous peasants were on the south side consisting of two neighborhoods called Xinchuan and Muxi (see Fig. 3). The four main residential neighborhoods were located in pairs on the north and south sides of a main public space axis.

The Erma Community and Yulong Community located on the north side were planned for the post-disaster migrants consisting of 5671 apartments, with the gross floor area of 564,000 square meters in total. The Xinchuan Community and Muxi Community located on the south were planned for the indigenous peasants consisting of 5516 apartments, with the gross floor area of 565,400 square meters in total.

Three resettlement housing types were designed for the migrants varying from 90 to 120 square meters ( $90 \mathrm{sqm}, 105 \mathrm{sqm}$ and $120 \mathrm{sqm}$ ). The arrangement of the apartments was randomly allocated by computer. Only the severely disabled people were allowed to choose the apartments on the first and second floor with priority.

\footnotetext{
${ }^{3}$ Resident population refers to people who continuously resided in New Beichuan for more than 6 months.

${ }^{4}$ Floating population refers to people who continuously resided in New Beichuan for less than 6 months. The floating population can be divided into two kinds of people (those arriving in the city and those leaving the city). In New Beichuan, most of the floating population are those who are leaving the city for better employment opportunities.

5 In the August of 2008, a preliminary resettlement plan was proposed by the China Academy of Urban Planning and Design. In the September of 2008, the Resettlement Master Plan after Wenchuan Earthquake was released by the State Council.
} 


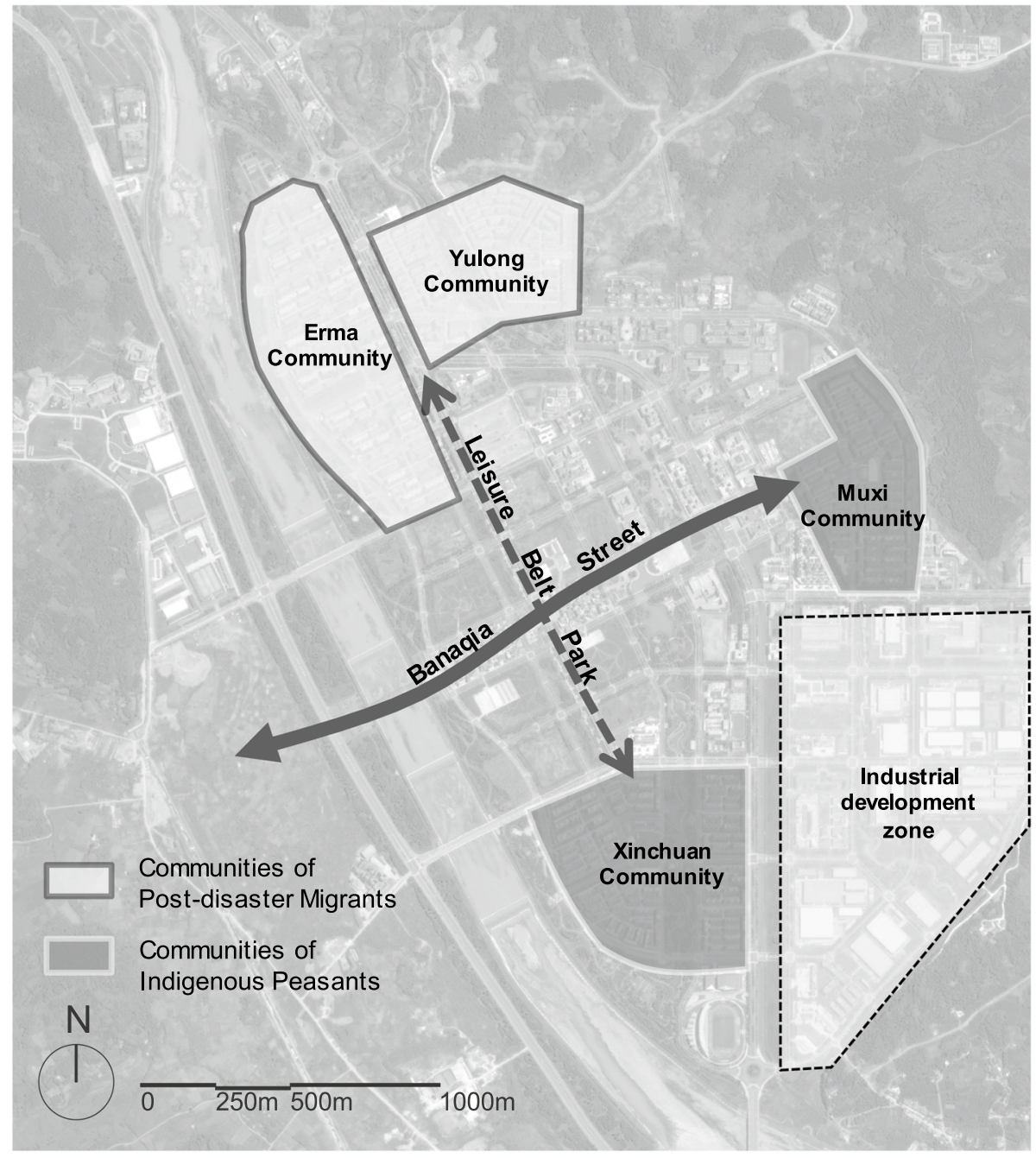

Fig. 3 Function zoning of New Beichuan Comprehensive Plan. (Source: Base map from Google Earth 2017 and elaborated by authors)

\subsection{Open space plan}

In the layout of the New Beichuan master plan, the open space system consisted of the riverside green space, a leisure belt park, an east-west public axis and the activity space of every neighborhood (see Fig. 7).

The riverside green space along the Anchang River served as the important public activity space and ecological corridor of the city. A leisure belt park, running from north to south along the Yongchang River as the main leisure space of the city, connected the important public facilities including the administration center, Huang'en Temple, the Earthquake Memorial Park, the gymnasium and the riverside park. An east-west axis 
connected the east and west parts of the city across the river, which consisted of a commercial street of strong Qiang elements, a central park and an administration center. Every neighborhood had its own activity space and was planned adjacent to the large public green area to share the environmental advantage.

\subsection{Open community construction and public facilities allocation}

The spatial plan of the communities was according to the thoughts of "Neighborhood Unit" (Perry 1998). In the plan, the central area of every neighborhood consisted of public facilities including a kindergarten, food market and community center, which were close to the large green area.

In order to construct open communities which promote self-managed housing clusters with positive connections to the living streets (Yu and Mu 2011) in New Beichuan, the living streets divided the community into different units and the area of each unit was between 1.1 and 2.1 ha (Xie 2014). One to two blocks formed an individual living cluster and were equipped with certain activity spaces, exercise facilities, pavilions and chairs for resting. Shops were located along most streets or the living neighborhoods which envisaged to construct open communities and to promote local employment.

In the layout of the resettlement plan, a commercial street called "Banaqia" was placed as a cultural axis and the core business area in the center of the four neighborhoods on the east-west direction (see Fig. 3), to promote the tourism and economic development of the city. In addition, an industrial development district was set on the southeast side (see Fig. 3) as a catalyst to the local economic development and compensation for the aided reconstruction of Shandong Province, in which companies from Shandong Province were introduced without payment for the land (source: from interviews with the community leaders). Furthermore, as the only Qiang Autonomous County in China, lots of Qiang elements were also integrated into the master plan on architectural and space design as a response to the ethnic features of Old Beichuan.

Planning intentions could be found in the open space and public facilities plan to help promote the local economic development, increase employment and integrate the postdisaster migrants and the indigenous peasants into the new space and new neighborhoods more easily.

\section{Differentiation on identity and resettlement policies between the post-disaster migrants and the indigenous peasants}

Differences could be found between the post-disaster migrants and the indigenous peasants on ethnicity and residence identities, and resettlement policies.

\subsection{Different ethnic and residence identities}

As the only Qiang Autonomous County in China, 48\% of the population of the Old Beichuan County belong to the Qiang ethnic minority, which occupied $94.9 \%$ of the whole minority population in the Old Beichuan County (Hu 2012). However, in contrast to the Old Beichuan County, most people of the An County did not belong to any minority group. In addition, most of the post-disaster migrants were urban registered residents who were used to living an urban life, while all the indigenous peasants were rural registered 


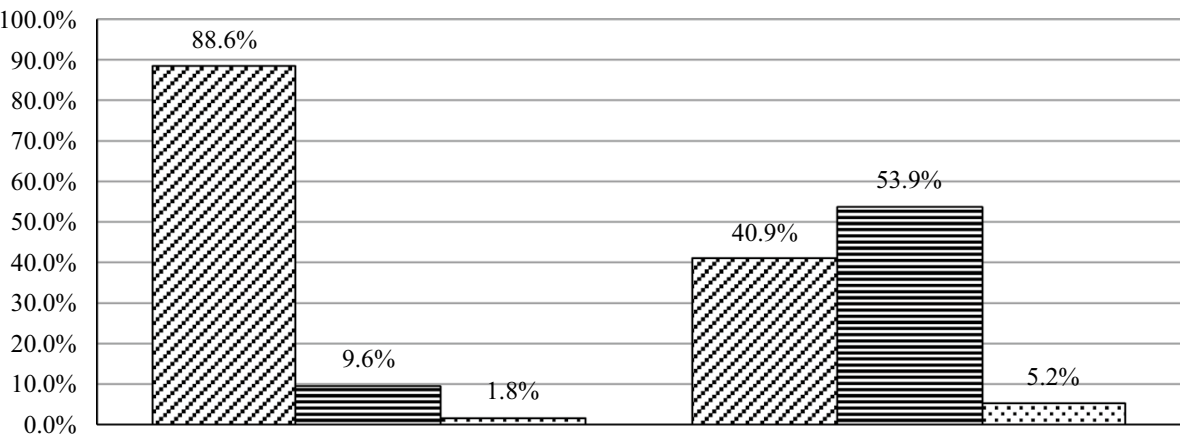

Communities of Indigenous Peasants

Communities of Post-disaster Migrants
圆 Han
目 Qiang
응 Other Ethnic Minorities

Fig. 4 Population constitution on nation identity of the respondents. (Source: From questionnaires and interviews)

residents who were used to living in the rural environment. This led to the different population constitution on nation and living modes between the post-disaster migrants and the indigenous peasants (see Fig. 4).

\subsection{Different resettlement policies}

In addition to the identity discrepancies mentioned above, the resettlement policies between the post-disaster migrants and the indigenous peasants were also different due to different resettlement situations.

For the indigenous peasants, the compensation policies involved material compensation and residence registration transformation. In the first place, cash compensations were given for the deprivation of their land and architecture. In addition, settlement housing compensation was also provided according to the numbers and constitution of their family members free of charge. For excessive housing area, 1600 RMB per square meter needed to be paid by themselves (see Table 3). In the second place, the local farmers could transform from agricultural residence registration (Hukou) to urban residence registration (Hukou) (see Table 3) and enjoy the city-dweller subsidies.

Conversely, the settlement policies for the post-disaster migrants were quite different. The resettlement cost was divided into four situations, according to whether they had self-owned proprietary or census registered identity (Hukou) of the Old Beichuan. For example, migrants with no proprietary and census registered identity had to pay for the settling housing at the cost price of 3200 RMB per square meter. And migrants who had self-owned housing and census registered identities could gain the settlement housing with only $600 \mathrm{RMB}$ per square meter, which was much lower than the cost price of the housing. Even so, the cost of the settlement of a three-person family could still be more than 100,000 RMB. The bigger the families were, the larger houses and more money were required.

Due to the different relocation policies, most post-disaster migrants spent 40,000-80,000 RMB for the housing reallocation on average; meanwhile, most indigenous peasants received 50,000 RMB to $10,000 \mathrm{RMB}$ due to the architectural and land compensation. 


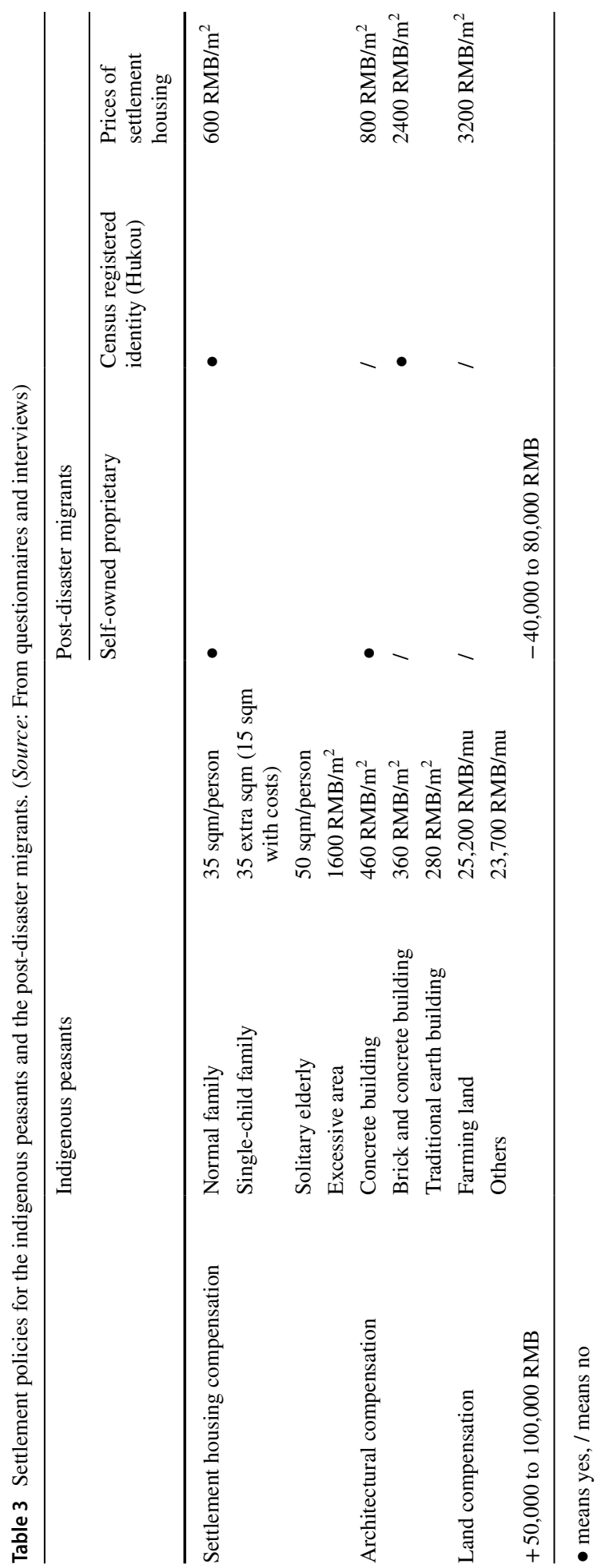


Although the government provided the post-disaster migrants with interest-free loans for 5 years, the average 10,000 RMB reimbursement per year was still a big pressure when the average monthly income in New Beichuan was only less than $2000 \mathrm{RMB}$, and the lowest might be below 1000 RMB every month. Even the highest salary of the community leaders was only 2300 RMB (source: from interviews with the residents and community leaders).

After the earthquake, the Old Beichuan was reserved and protected as the earthquake ruins for tourism, and all the survivors who would be resettled to New Beichuan devoted their ownership of their immovable properties in the Old Beichuan to the government voluntarily (source: from interviews with the residents and community leaders). However, the economic development of the New Beichuan did not perform well. Local employment opportunities were lacking, and the average income of the local employment was low. So when the survey was conducted in 2015,5 years after the reconstruction, most Old Beichuaners were still in debt.

According to the investigation and data of questionnaire, the family expenses of postdisaster migrants were 1.8 times higher than the indigenous peasants, and the liabilities of post-disaster migrants were 2.3 times more than the indigenous peasants. The more expenses they paid during the resettlement process, the worse their economic conditions were after the resettlement.

Different settlement policies between the original tenants and the post-disaster migrants led to different expenditures and liabilities of households during the recovery and a certain degree of psychological imbalance and discontent between the two groups of people.

\section{Spatial integration and differentiations}

Based on statistic analysis of the interviews, questionnaire data and observation on the usage of the built environment, problems could be found in the following aspects:

(1) Quality problems of housing

(2) Neighborhoods management and security concerns.

(3) Contradictions between the housing layout and local living habits

(4) Different utilization preferences of open space between the indigenous peasants and the post-disaster migrants

(5) Supply and demand mismatch/disequilibrium of public facility allocation.

\subsection{Quality problems of resettlement housing}

Quality problems generally occurred in the resettlement housing apartments. In the survey of the housing problems, $53.9 \%$ of residents (see Fig. 5) pointed out that quality problems were the most prominent housing problems.

The quality problems of the resettlement housing could be mainly divided into two categories. First were the design problems due to insufficient designing consideration of the local rainy climate, such as pipe plugging and windows leaking. Second were the construction problems, including the ceiling leakage, wall cracking and flaking. Those problems were probably caused by the tight project schedule and fast reconstruction process, and some problems in the supervision of the housing design and construction quality. 


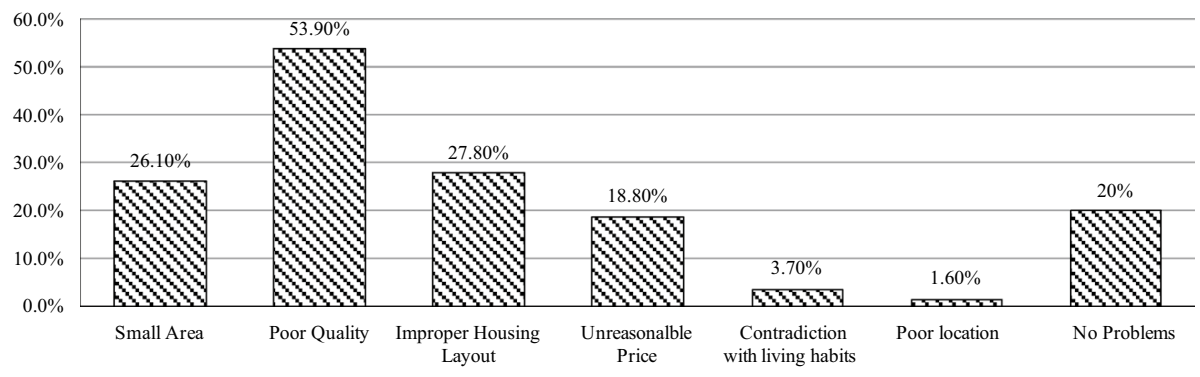

Fig. 5 Problems of resettlement housing. (Source: From questionnaires and interviews)
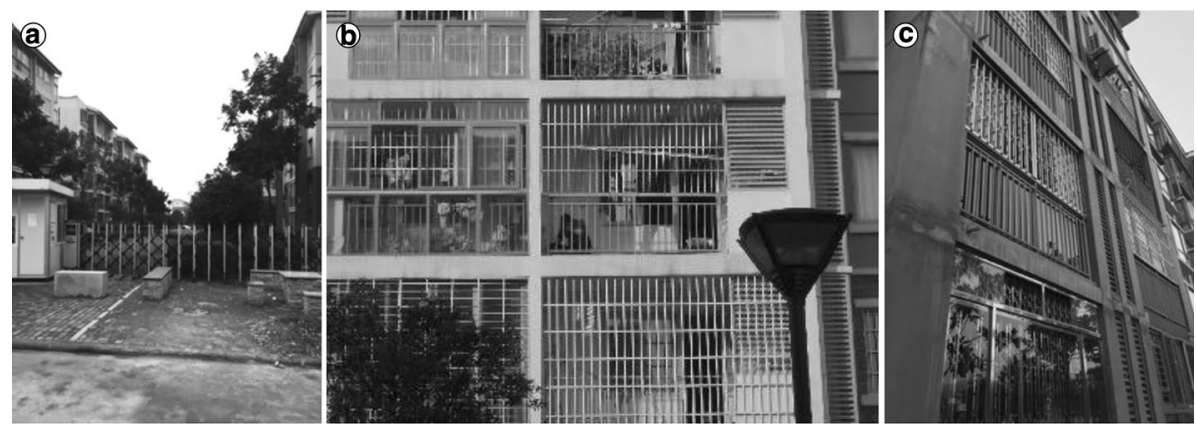

Fig. 6 Closed community gates of Yulong Community (a) and burglary-resisting windows installed by residents $(\mathbf{b}, \mathbf{c})$. (Source: Photograph taken by authors)

Due to the wide range, complexity and easy recurrence of the housing quality problems, it was quite difficult and expensive to carry out the maintenance continuously, which made it a thorny issue that troubled the local community management and residents' lives.

\subsection{Neighborhoods management and security concerns}

According to the survey, security problems were prevalent in both the post-disaster migrants and the indigenous peasants' communities. As a result of advocating the concept of open communities, the residential area was divided into small units by living streets and each community had lots of entrances. At the same time, railing walls were largely used to enhance the visual connection of neighborhoods.

For example, the Xinchuan Community was divided into six clusters. Each unit had one to two units, with a total of 10 units. Calculated with at least two entrances for each unit, there were more than 20 entrances to the community. For the consideration of management costs and community security, the property company had to close some entrances with low traffic to reduce the number of gatekeepers (see Fig. 6). And in the public pedestrian street of the Muxi Community, outsiders could freely enter the units and reach the building entrance, which greatly weakened the security facilities and brought some hidden dangers to residents' lives. According to the residents and community leaders, the number of lost bicycles and motorcycles increased significantly in the New Beichuan. As a result of 
the security consideration, burglary-resistant windows were installed by the most residents themselves (see Fig. 6).

In addition, different views on safety and security issues existed between the indigenous peasants and the post-disaster migrants. The indigenous peasants, who had been used to living in detached village houses, preferred to attribute the security problems to the physical issues including short walls and excessive entrances. The post-disaster migrants who were more familiar with city management preferred to believe that the security problems were caused by the management confusion and negligence. Judging from the status quo, problems of both physical planning and management existed. For the protection of residents' private property, the practice of open community living should be accompanied with more effective and efficient security management. Only if the safety and security of residents were guaranteed could the openness of communities be better achieved.

\subsection{Contradictions between the housing layout and local living habits}

Besides, housing types and areas also concerned the residents, accounting for $27.8 \%$ and $26.1 \%$, respectively (see Fig. 5). The main problems included the housing layouts and areas:

(1) The aisles occupied too much housing area;

(2) Kitchens and bedrooms were comparatively small in size and inconvenient to be used;

(3) The design of housing types and areas were monotonous and uniform. The housing types varied from 90 square meters to 105 and 120 square meters, which means that the original large families had to be broken down and live separately.

The inadaptability to housing layouts was comparatively more severe among the indigenous peasants. Compared with their original housing, the new housing type was not flexible enough. The sitting room was too small to hold large family gatherings. Toilets were too close to the kitchen and did not conform to their traditional living habits.

On the one hand, these problems could be ascribed to lacking considerations of local cultural and lifestyles. On the other hand, it was also due to the sudden passive transformation of the indigenous peasants from the style of rural life to urban life, which had caused their inadaptability. The inadaptability of the transformation was mainly reflected in two aspects, different living habits and employment. According to the interviews with the community leaders, some indigenous peasants refused to start working in the city and relied on the architectural and land compensation for a long time.

\subsection{Different utilizations of open space}

\subsubsection{Low utilization of cluster-level open space}

The open space in the city could be roughly divided into the city-level open space, community-level open space and the cluster-level open space (see Fig. 7). Low utilization of cluster-level open space with different usage preferences could be found between the community of post-disaster migrants and the community of indigenous peasants.

In both communities, the cluster-level open spaces were minimally used than the community- and city-level open spaces (see Fig. 7). According to the on-site investigation, it could be found that some community-level and city-level public spaces of good scale inside 


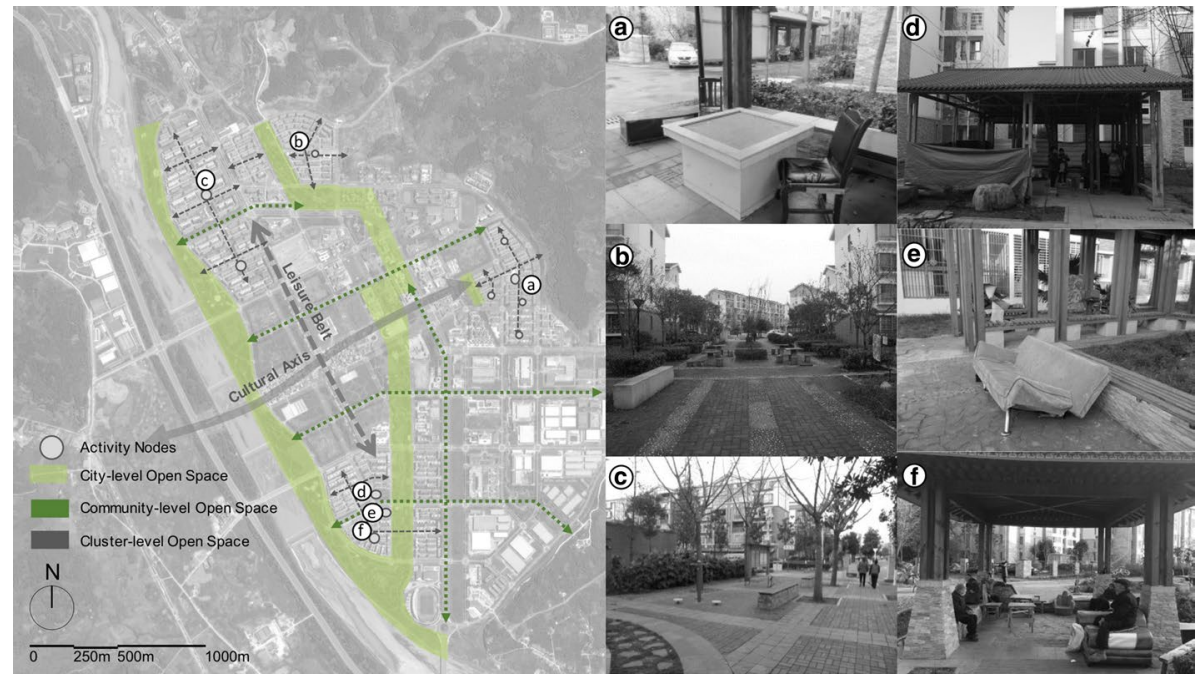

Fig. 7 Open space system of New Beichuan (a, b, c cluster-level open space of post-disaster migrants' communities; d, e, f cluster-level open space of indigenous peasants' communities; b, c some residents moved their spare sofa from home to the community open space for public usage. d Residents of Muxi Community spontaneously added canvas shelters to the open pavilions in the community to resist the cold climate in winter). (Source: Base map from Google Earth 2017 and elaborated by authors)
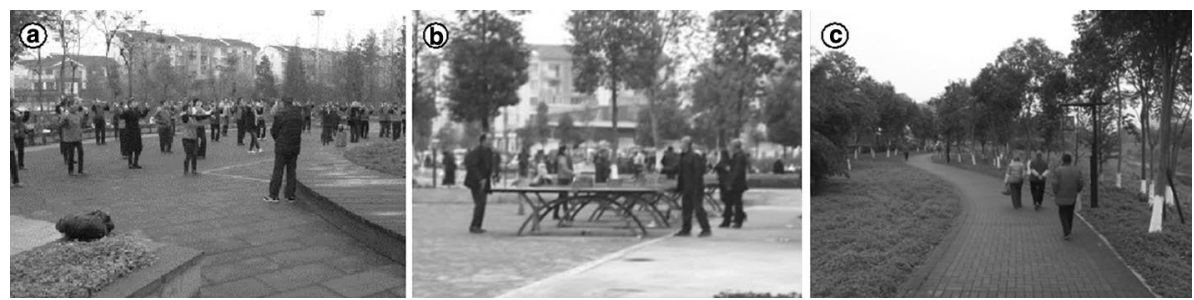

Fig. 8 City- and community-level open space of New Beichuan (a, b community-level open space; $\mathbf{c}$ riverside green space). (Source: Photograph taken by authors)

or near the neighborhoods with good accessibility were normally highly used, including the community centers, riverside parks and the main street space outside the neighborhoods. The residents were more willing to wander on the public streets, chat in front of the shops or play cards around a table at the community gate. Therefore, street space, community gates and community spaces equipped with sport and fitness facilities became one of the most popular public activities and outdoor social places for the residents (see Fig. 8), whereas the narrow interior public spaces inside the building clusters and some city-level public spaces such as the cultural axis and leisure belt between the two communities were comparatively less utilized (see Fig. 7b).

Based on the residents' feedback in the interviews, the low utilization of the smallscale public space inside the communities could partly be ascribed to two reasons. The first reason was the lack of maintenance of the landscape, poorly qualified community infrastructure and debased recreation facilities inside the communities. Lack of activity 
Fig. 9 Cabbage leaves on the railings. (Source: Photograph taken by authors)

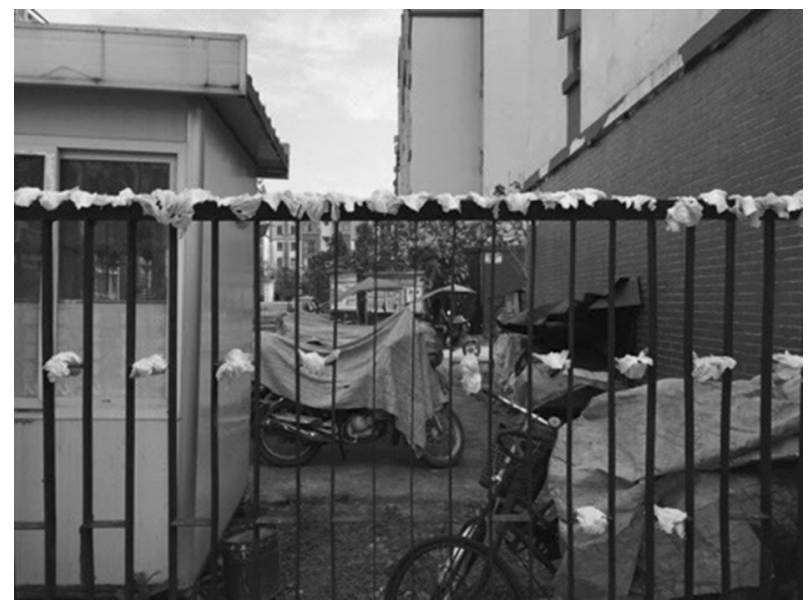

facilities which had been easily broken was the main reason for the low utilization of the cluster-level open space. In some cluster-level open spaces, there were no pavilions, tables, chairs and other facilities for resting. And some residents of the indigenous peasants' community chose to put some old, poor-quality tables and chairs, or sometimes stones as chairs in the cluster-level open spaces for the public use. The second reason was the poor spatial feeling of over-enclosed space forms. Some residents also presented their dislike of the over-enclosed space forms. Due to the investigation, most cluster-level open spaces were placed between the buildings, which made the space scale narrow, and a lack of sunlight might lead to poor spatial feeling.

\subsubsection{Different spatial use preferences between two communities}

Different spatial use preferences of green space and cluster-level open space could be found between the post-disaster migrants and the indigenous peasants.

Compared to the indigenous peasants, the post-disaster migrants living in the Erma and Yulong neighborhoods used the green public spaces more often. In the community of indigenous peasants, the open green space was not so attractive to the residents. Only green space on the roadsides with fitness equipment was used more often. According to interview of the community leaders, the indigenous peasants did not regard the urban public green space as an important landscape resource because they had been living with the vast rural scenery for a very long time. They even called the centralized urban green space "half-side-change," which means a half is the city and another half is the countryside. They also regarded the green space as a kind of hindrance to their daily trips. On the contrary, they were more interested in the hard-paving open space due to the shortage of the hard-paving space in their original villages.

Also, differentiations on the usage of cluster-level open space existed between the community of post-disaster migrants and the community of indigenous peasants. In the indigenous peasants' community, an interesting phenomenon was that some agricultural activities often occurred in the cluster-level open space such as putting the cabbage leaves on the railings, public chairs or stones in pavilions to make pickled vegetables (see Fig. 9). 


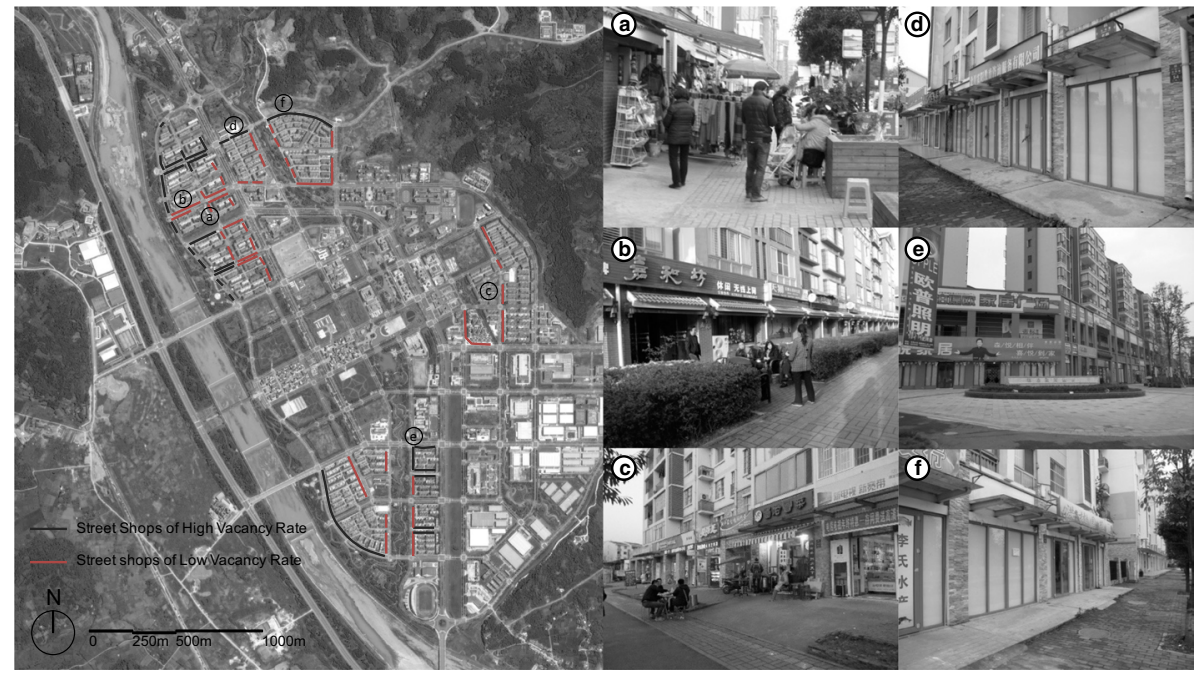

Fig. 10 Vacancy of street shops in New Beichuan (a, b, $\mathbf{c}$ street shops of low vacancy rates; $\mathbf{d}, \mathbf{e}, \mathbf{f}$ street shops of high vacancy rate). (Source: Base map from Google Earth 2017 and elaborated by author, photographs taken by authors)

The mismatches of the usage and planning intention of public spaces also reflected the shortage of research and consideration for local cultural and different living habits (Marcillia and Ohno 2012) between the two groups of different people.

\subsection{Supply and demand disequilibrium of public facility allocation}

In the survey, $49.8 \%$ of residents thought that shortage of public facilities was the main problem in community development.

However, according to the on-site investigation, a certain proportion of commercial facilities and the tourism facilities were vacant and lack vitality. Disequilibrium could be found with the supply and demand of public facilities, which mainly reflected on (1) vacancy of commercial infrastructure, and (2) monotonous function of tourism facilities hindered the spatial integration.

\subsubsection{Vacancy of commercial infrastructures}

In terms of commercial facilities, the vacancy rate of shops in residential areas was relatively high. Although the main street space of the central area was vivid, large numbers of the street shops on the fringe of the communities were empty (see Fig. 10), reflecting the depression of commercial vitality. Most of the surviving shops were restaurants or those who were selling retail products and daily necessities like supermarkets, while others like shops providing automobile service or souvenir shops were being painstakingly operated.

According to the staff of the Muxi Community Center, despite the implementation of a tax exemption policy on store renting, there were still around one-third of street shops unleased in the Muxi Community and even the rented shops were not all in operation. However, the one-third vacancy rate of street shops was comparatively not as high as other 
Table 4 Population of four neighborhoods. (Source: From questionnaires and interviews with community leaders)

\begin{tabular}{lllc}
\hline & Resident population & Floating population & Total population \\
\hline Erma Community & 7568 & 3000 & 10,568 \\
Yulong Community & 4980 & 3660 & 8640 \\
Xinchuan Community & 6763 & 600 (approximate number) & 7363 \\
Muxi Community & Data missing & Data missing & 6350 \\
\hline
\end{tabular}

areas due to the good location and accessibility of the Muxi Community. The situation of the commercial infrastructure operation in other communities was even more depressing.

In addition, the construction of food markets was also not so optimistic. Although the food markets were located in the center of each community, residents still preferred to purchase their daily supplies in Huangtu Town as the prices were lower. It reflected the gap between the commercial infrastructure development and purchase power of the local residents.

The relatively high commercial infrastructure vacancy rate might attribute to the population and consumption structure of the residents. In the survey of family employment, $35 \%$ of families had a family member working in another city (see Table 4). The local employment difficulty, caused by the management failure and vacancy of the industrial development district, contributed to the outflow of young people with stronger spending power. The resident population in the city mainly consisted of elderly people, woman and children with limited spending power.

On the other hand, different groups of people had different requirements for commercial infrastructures. Compared with the post-disaster migrants, the indigenous peasants had long been engaged in agricultural activities and were not likely to use business activities. Some residents of the indigenous peasants' community living on the ground floor even changed their housing to grocery stores and were selling some daily supplies without the cost of rent. Therefore, they were not accustomed to dense, small family living with independent retail space and were more reluctant to rent the street shops.

These aspects explained the contradictions between the demand for commercial infrastructure in the planning phase and the insufficient utilization and vacancy of those facilities after reconstruction. Restricted by the former living habits and economic level, the indigenous peasants were more likely to use the low-cost and public welfare service facilities than the post-disaster victims. Also the outflow of the working population decreased the requirement for commercial facilities. Therefore, typical urban housing design and socioeconomic construction of the new town development might not be totally appropriate for the unstable social and economic reconstruction process of after-disaster off-site resettlement.

\subsubsection{Dominant external function of tourism facilities weakened the integration potential}

The "Banaqia" commercial street between the two communities was defined as the central commercial district for the citizens and the cultural axis with "Qiang" ethnic features for external tourists. However, the dominant external tourism functions of the commercial street had little connection and relationship with the local residents. Neither the post-disaster migrants nor the indigenous peasants had chances to use the space and commercial facilities of the "Banaqia" streets, which weakened the internal integration potential for the communal shared space. In addition, as the main public space for tourism, the "Banaqia" street was operated 
worse than expected. The shops and products on the streets were of high homogeneity. Tourists were mainly from the cities nearby for weekend's excursion and rarely stayed overnight.

Therefore, the main public space axis planned for potential integration turned out to be an obvious physical barrier instead of the integration hub between the two main residential communities.

\section{Discussion and conclusions}

The earthquake brought enormous casualties and property loss to the Beichuan County. The reconstruction had received extensive attention from the whole society. The off-site resettlement and site selection not only increased the difficulty of reconstruction, but also increased the complexity of population composition of the new city and made the residents' requirements for the living space more diverse.

As the only off-site relocation project among the dozens of rebuild cases, New Beichuan started from zero. The relocation process was completed in less than 3 years with strong intervention from the government, who provided both the huge financial assistance and the overall reconstruction planning through a counterpart support plan. Compared with the long period of other post-disaster resettlements (see Table 1), the rapid government-oriented top-down resettlement process of Beichuan (Liu et al. 2014) did well for efficiency, ensuring the basic living requirements of the victims. An obvious integration motivation of the resettlement plan could be found to assist the post-disaster migrants and the indigenous peasants to be integrated into the new place and new communities.

The strong leadership of the government in the resettlement process of New Beichuan did efficiently solve the practical problems of displacement and met the urgent needs of victims in a short time. Nonetheless, the excessive pursuit of speed also contributed to insufficient attention to spatial, social and economic aspects and led to inevitable and longstanding problems, including (1) housing quality problems; (2) management and security concerns; (3) contradictions between the housing layout and local living habits; (4) different spatial usage preferences between the indigenous peasants and post-disaster migrants; and (5) disequilibrium of public facility allocation. And reasons could be ascribed to the aspects of (1) site selection, (2) spatial layout, housing design and construction, (3) economic development and (4) population participation (Oliver-Smith 1991).

First, the site of the New Beichuan was selected on a farmland of flat terrain, under the situation of government orientation, for the ease of land acquirement and construction. However, the lack of concern for transportation advantage and resource superiority of the site could lead to the difficulty in economic development (Oliver-Smith 1991).

Second, in terms of the spatial layout, housing design and construction of the resettlement, a great many of problems occurred due to varieties of reasons. Monotonous uniform design was presented to meet the needs of easy and rapid construction, which resulted in a lack of variety on the housing design (Oliver-Smith 1991). The time limitation of the construction also brought about faulty construction and housing quality problems. Moreover, the aided reconstruction from the province with totally different climate and living habits could result in an inappropriate design for domestic activities of both the post-disaster survivors and the indigenous peasants.

Third, self-sustained economic development and sufficient viable employment opportunities are considered as irreplaceable and crucial issues of a successful resettlement (Cernea 1988; Partridge 1989; Oliver-Smith 1991). However, the reconstruction of the city did not perform well in these aspects. In the first place, property abandonment, high cost of entry for the earthquake victims and their low income after the resettlement made lots of survivors 
be in debt for a long time (Zhang and Peacock 2009). In the second place, the failed economic development attempts of the industrial park and tourist-oriented center led to inadequate local employment opportunities, outflow of the workforce and large dead spaces in the city. The shortage of employment opportunities in the new resettlement environment also reduced the potential of reestablishing and integrating a new social and economic organization of the post-disaster victims and the indigenous peasants (Oliver-Smith 1991).

Fourth, population participation throughout the entire process of the resettlement was lacking. Residents only acknowledged the plan for agreements, rather than being involved in the reconstruction and decision-making process.

All in all, the reconstruction of the New Beichuan is a case with specificities, including the particularity of reconstruction methods, reconstruction subjects and population constitution of the migrants. Various problems turned up during the resettlement process. Based on the research and findings, lessons and valuable experience could also be learned from the distinct top-down off-site resettlement planning practice.

(1) An environment easier for development is as important as and sometimes more crucial than an environment easier for reconstruction, so that both the spatial reconstruction and socioeconomic development should be considered regarding the site selection and policy support of an off-site post-disaster resettlement.

(2) More population participation should be considered throughout the entire process of reconstruction, so that more useful suggestion could be input in the planning and design of residential areas (Lizarralde 2011).

(3) More rigor economic studies could have been included in the planning process, which might have revealed the impropriety of industrial park and lack of demand for extensive tourism services (Barenstein and Pittet 2007).

Nonetheless, the findings of this study should be considered in light of some limitations, including the potential sample bias of community questionnaire, the imperfection of questionnaire design and the limitation of social economic data acquirement. First, the questionnaires handed out and collected by the community staff could be not absolutely randomly conducted and failed to present the opinions of the whole population. Second, some questions related to crucial findings had not been considered in the questionnaire, because the questionnaire was prepared based on the literature review before the community interview and site investigation. But when being aware of the problems during the interviews, we immediately added the related questions to the interviews of the community leaders and residents during the on-site investigation for the qualitative feedback. Third, due to the limitation of data acquirement, detailed social and economic data which might help giving more persuasive analysis were lacking in this study. In summary, investigation with more specific objectives and rigorous sampling methods, and more detailed geographic information analysis, will be helpful to make improvement in the further studies.

Acknowledgements The authors would like to acknowledge the kind help of all the interviewees including the residents and community leaders from Erma, Yulong, Muxi and Xinchuan Communities, and officers from the government of New Beichuan. In addition, great gratitude should be given to special contribution of $\mathrm{Wu} \mathrm{Lu}$ and Yang Qianwen to the on-site field research investigation and investigation data analysis.

Open Access This article is distributed under the terms of the Creative Commons Attribution 4.0 International License (http://creativecommons.org/licenses/by/4.0/), which permits unrestricted use, distribution, and reproduction in any medium, provided you give appropriate credit to the original author(s) and the source, provide a link to the Creative Commons license, and indicate if changes were made. 


\section{References}

Agence France-Presse (2008) More than 4.8 million homeless in Sichuan quake: official. http://www.relie fweb.int/rw/RWB.NSF/db900SID/PANA-7EPG6V?OpenDocument. Accessed 7 July 2008

Baidubaike (2018) New Beichuan County (in Chinese). https://baike.baidu.com/item/北川新县 城/3341319?fromtitle=新北川县城 \&fromid $=15482939 \&$ fr=aladdin. Accessed 25 Jan 2018

Barenstein JD, Pittet D (2007) Post disaster housing reconstruction current trends and sustainable alternatives for tsunami-affected communities in coastal Tamil Nadu. Institute for Applied Sustainability to the Built Environment, University of Applied Sciences of Southern Switzerland, Canobbio

Blanco H, Alberti M, Olshansky R, Chang S, Wheeler SM, Randolph J et al (2009) Shaken, shrinking, hot, impoverished and informal: emerging research agendas in planning. Prog Plan 72(4):195-250

Briggs XNDS, Wilson WJ (2005) The geography of opportunity: race and housing choice in metropolitan America. Brookings Institution Press, Washington, DC

Cernea MM (1988) Involuntary resettlement in development projects: policy guidelines in World Bankfinanced projects. The World Bank, Washington, DC

China Earthquake Administration (2008) Analysis of the cause of the M8.0 Wenchuan earthquake (in Chinese). http://www.cea.gov.cn/manage/html/8a8587881632fa5c0116674a018300cf/_conte nt/08_05/30/1212119940937.html. Accessed 7 Sept 2008

China Earthquake Administration (2009) The aftershock distribution and statistics of Wenchuan earthquake due to February 62009 (in Chinese). http://www.cea.gov.cn/manage/html/8a8587881632fa5c0116 674a018300cf/_content/09_05/27/1243412097620.html. Accessed 27 May 2008

Coburn AW, Leslie JD, Tabban A (1984) Reconstruction and resettlement 11 years later: a case study of Bingol Province, Eastern Turkey. In: Schupisser S, Studer J (eds) Earthquake relief in less industrialized areas. A.A. Balkema, Rotterdam, pp 49-58

Cutler DM, Glaeser EL (1995) Are ghettos good or bad? (No. w5163). National Bureau of Economic Research

Danziger S, Haveman RH (2001) Understanding poverty. Harvard University Press, Harvard

Davidson CH, Johnson C, Lizarralde G et al (2007) Truths and myths about community participation in post-disaster housing projects. Habitat Int 31(1):100-115

Government Website of Beichuan (2018) Beichuan Year Book of Beichuan Qiang Autonomous County (2017) (in Chinese). http://www.beichuan.gov.cn/content.jsp?id=8a868a34628e2a3f0163d8ee83bc4f 2f\&classid $=\mathrm{f} 698 \mathrm{a} 0474052445194662 \mathrm{~d} 053 \mathrm{a} 1 \mathrm{~b} 49 \mathrm{~d} 4$. Accessed 10 Feb 2019

Henry CM (2004) Race, poverty, and domestic policy. Yale University Press, New Haven

$\mathrm{Hu} \mathrm{XC}$ (2012) Population migration and distribution problem in earthquake disasters area (in Chinese). (Doctoral dissertation, Southwestern University of Finance and Economics)

Huaxi City News (2010) The government of New Beichuan was founded (in Chinese). http://news.163. com/10/0131/05/5UB5EN52000120GR.html. Accessed 31 Jan 2010

Iceland J (2009) Where we live now: immigration and race in the United States. University of California Press, Berkeley

Johnson LA (2008) Longer view: planning for the rebuilding of New Orleans. J Am Plan As 74(3):273-287

Kawachi I, Lisa FB (2003) Neighborhoods and health. Oxford University Press, Oxford, p 265

Lan DX (2011) A comparative study of characteristics of post-earthquake reconstructions abroad and the experience of "5.12" post-earthquake reconstructions in China. J Chengdu Univ (Soc Sci Ed) 2011(4):6-8 (in Chinese)

Levine JN, Esnard AM, Sapat A (2007) Population displacement and housing dilemmas due to catastrophic disasters. J Plan Lit Inc the Cpl Bibliogr 22(1):3-15

Liu L, Lin Y, Wang S (2014) Urban design for post-earthquake reconstruction: a case study of Wenchuan County, China. Habitat Int 41(1):290-299

Lizarralde G (2002) Organizational design, performance and evaluation of post-disaster reconstruction projects. In: Proceedings of the first international conference on post-disaster reconstruction: improving post-disaster reconstruction in developing countries, pp 23-25

Lizarralde G (2011) Stakeholder participation and incremental housing in subsidized housing projects in Colombia and South Africa. Habitat Int 35(2):175-187

Ma WZ, Yang ZH (2010) Off-site reconstruction pattern of the new county of Beichuan. Adm J Sichuan Sch 3:40-43 (in Chinese)

Marcillia SR, Ohno R (2012) Learning from resident's adjustments in self-built and donated post disaster housing after java earthquake 2006. Procedia Soc Behav Sci 36:61-69

Massey DS, Denton NA (1993) American apartheid: segregation and the making of the underclass. Harvard University Press, Harvard 
Momeni JA (1986) Race, ethnicity, and minority housing in the United States. Greenwood Press, Inc., 88 Post Road West, Box 5007, Westport, CT 06881

Murdie RA (2001) Ethnicity and housing: accommodating differences, Frederick W. Boal. J Hous Built Environ 16(3-4):341-343

Oliver-Smith A (1990) Post-disaster housing reconstruction and social inequality: a challenge to policy and practice. Disasters 14(1):7-19

Oliver-Smith A (1991) Successes and failures in post-disaster resettlement. Disasters 15(1):12

Partridge WL (1989) Involuntary resettlement in development projects. J Refug Stud 2:373

Perry C (1998) The neighbourhood unit (1929). Reprinted Routledge/Thoemmes, London, pp 25-44

Scudder T, Colson E (1982) From welfare to development: a conceptual framework for the analysis of dislocated people. In: Involuntary migration and resettlement; the problems and responses of dislocated people, pp 267-287

Sharkey P (2013) Stuck in place: urban neighborhoods and the end of progress toward racial equality. University of Chicago Press, Chicago

Sina News (2008a) The surviving population in Beichuan has reached 13600 people (in Chinese). http:// news.sina.com.cn/c/2008-05-17/160615561444.shtml. Accessed 17 May 2008

Sina News (2008b) Casualties of the Wenchuan Earthquake (in Chinese) http://news.sina.com.cn/pc/200805-13/326/651.html. Accessed 6 July 2008

Xie L (2014) Assessment of the openness of the reconstructed urban community environment after the Wenchuan earthquake (in Chinese). (Doctoral dissertation, Southwest Jiaotong university)

Yi H, Yang J (2014) Research trends of post disaster reconstruction: the past and the future. Habitat Int 42:21-29

Yu W, Mu Y (2011) The application of community concept in the neighborhood planning-a case study of the Hongqi resettlement area planning New Beichuan. Planner 9:65-68 (in Chinese)

Zhang Y, Peacock WG (2009) Planning for housing recovery? Lessons learned from Hurricane Andrew. J Am Plan As 76(1):5-24

Publisher's Note Springer Nature remains neutral with regard to jurisdictional claims in published maps and institutional affiliations.

\section{Affiliations}

\section{Yisha Zhang ${ }^{1,2} \cdot$ Yifan $\mathrm{Yu}^{1}\left(\mathbb{D} \cdot\right.$ Wenjuan $\mathrm{Xu}^{1,3} \cdot$ Jingjing $\mathrm{Hu}^{4}$}

Yisha Zhang

yishazhang_cn@126.com

Wenjuan Xu

xuwenjuan20070940@163.com

Jinging $\mathrm{Hu}$

13488871351@139.com

1 College of Architecture and Urban Planning, Tongji University, No.1239 Siping Road, Shanghai 200092, People's Republic of China

2 Aecom Ltd, No.500 Zhengli Road, Shanghai 200433, People's Republic of China

3 Zhejiang University Urban-Rural Planning and Design Institute, No.199 Shuanglong Street, Hangzhou 310012, People's Republic of China

4 China Academy of Urban Planning and Design, Beijing, People's Republic of China 